\title{
AS CORES DO ÓDIO: IMAGENS DO ÓDIO RACIAL EM ABSALÃO, ABSALÃO! DE FAULKNER
}

ISÉE BERNATEAU

Isée Bernateau Universidade Paris VII Diderot, Professora do Centro de Pesquisa Psicanálise, Medicina e Sociedade, Paris, França.
RESUMO: A partir do romance Absalão, Absalão!, de Faulkner, pretendemos estudar as diferentes imagens do ódio racial presentes nessa obra. Esta forma específica de ódio pretende diferenciar brancos e negros, o mais precisamente possível, para que assim se evite qualquer risco de amálgama e de confusão, vivenciadas como essencialmente incestuosas. Este ódio é mosaico e narcisista, e visa preservar o ego ao mesmo tempo em que o projeta para fora e destrói todo inimigo interno que possa vir a comprometer sua supremacia. Mas este ódio destina-se sobremodo a esconder o amor da mãe-terra, tão profundo quão secreto.

Palavras-chave: ódio racial; escravidão; incesto; amor materno.

ABSTRACT: The colors of hatred in Absalom, Absalom!, of Faulkner. Drawing upon Faulkner's Absalom, Absalom!, the author sets out to put the assorte expressions of racial hatred under study. This particular form of hatred entails establishing a clear-cut distinction between the White and the Black in order to forestall conflation and confusion, both of which are perceived as deeply incestuous. This hatred is ego-related and narcissistic, with the purport of protecting the ego through projection on to the outside environment, as well as destruction of any enemies that jeopardise its supremacy. This hatred, however, first and foremost endeavours to conceal a deep-seated, secret love for Mother Earth.

Keywords: hatred; slavery; Mother Earth; incest.

DOI - http://dx.doi.org/10.1590/1809-44142017003009 
magem específica do ódio, ainda que paradigmática, o ódio racial fixa, com uma mórbida precisão, as fronteiras entre o eu e o outro, inventando assim sociedades dentro das quais a tez da pele determina radicalmente a identidade e o destino dos indivíduos. A tez da pele, esta "grande diferença", está na base - tanto nos estados sulistas dos Estados Unidos ao começo do século XX, quanto na totalidade do mundo colonial - de um imaginário da pureza branca que uma gota apenas de sangue negro poderia corromper para sempre. A one-drop rule, lei da gota de sangue, adotada em 1924 nos estados do sul, chega ao ponto de considerar "como negra qualquer pessoa que descenda de, ao menos, um negro vindo da África pelo intermédio da escravidão, pouco importa o número de uniões interraciais das quais aquela seja fruto" (PERETZ, 2013, p. 11). Segundo o princípio dito de hipodescendência, esta lei atribui um estatuto social inferior a todo aquele que seja descendente de um casal misto. Esta lei tem, assim, o poder de transformar um branco em negro em nome desta invisible darkness que assegura proteção a todo custo para a parcela branca da sociedade. Ela levanta uma barreira intransponível entre negros e brancos, cerceando o negro e o branco dentro de uma lógica binária - ao mesmo tempo, exclusiva e antagônica -, que impede toda e qualquer mestiçagem.

Publicado em 1936 - tal como E o vento levou!, do qual ele é a antítese total -, Absalão, Absalão!, de Faulkner, relata, segundo seu próprio autor, "a destruição relativamente violenta de uma família, entre 1860 e 1910" (Carta de Faulkner para Harrison Smith, fevereiro de 1934, in: FAULKNER, 1936/1995, p. 1328). A dinastia dos Sutpen, fundada por Thomas Sutpen - branco pobre de origem escocesa, white trash, que veio com seu pai e irmãs das montanhas da Virgínia para o sul do Mississipi -, conhece um destino trágico cuja dimensão bíblica, presente no título, desdobra-se magistralmente ao longo do romance. Contada por quatro narradores cujas vozes se sucedem e se confundem, se respondem e se contradizem, a história da família Sutpen é violenta e, nela, o papel do ódio é preponderante - até mesmo matricial: "É Quentin Compson, de $O$ Medo e a Fúria, quem conta a história ou, ao mesmo, cria sua unidade. (...) Utilizo a amargura com que ele enxerga o sul sob a forma de um ódio profundo por essa região e seu povo; assim, posso absorver ainda mais a essência história do que um romance de história propriamente dito. Assim, não se acharão nem crinolinas e muito menos cartolas por aqui" (ibid., p. 757). O panorama histórico, com seus lugares-comuns mistificadores e idealizadores, dão então lugar à realidade escondida: o ódio racial!

Ódio de brancos para com brancos, tal como o da senhorita Rosa Coldfield, a primeira narradora, esta idosa branca do sul "aprisionada desde 43 anos em sua velha carapaça, o antigo ressentimento escandalizado" (ibid., p. 776). Após haver odiado, por razões misteriosas, seu próprio pai, ela odeia ainda mais Thomas Sutpen, o homem branco que se casou com sua irmã Ellen, e com a qual teve dois filhos, Judith e Henry. Este ódio àquele que ela considerava "um ogro, uma besta feroz qualquer que teria escapado de uma história de terror para crianças" é descrita como uma modulação fundamental do relacionamento em uma economia pulsional que visa preservar, o quanto for possível, as investidas do objeto: "Talvez seja realmente necessário conhecer bastante alguém para se poder amá-lo, mas, quando se odeia alguém durante 43 anos, ele já se faz suficientemente conhecer e, talvez, seja melhor assim, pois, depois de 43 anos, não se pode mais causar qualquer tipo de surpresa, prazer ou ataque de cólera" (ibid., p. 617-618). Este ódio, preciosamente cuidado durante uma vida inteira, tornou-se para a senhorita Rosa mais do que uma razão de vida: tratava-se de uma substância vital sem a qual não se pode mais viver ("o ódio é como o álcool ou uma droga e ela o havia consumido durante tanto tempo que não ousaria correr o risco de impedir seu fornecimento, de destruir sua fonte, sua raiz e a semente da papoula" [ibid., p. 927]). Marcando o ritmo, o ódio conserva e anima um corpo magricelo e fatigado: "mas nem tu podeste impedi-lo, pois 43 anos de ódio tinham deixado tantas sequelas quanto 43 quilos de carne crua". Objeto e sujeito autênticos de ódio, o branco Thomas Sutpen, figura faulkneriana do chefe da tribo, aparece na versão que a senhorita Rosa conta a Quentin Compson como a visão alucinante do próprio diabo, invertendo assim ironicamente o gesto demiúrgico em um de maldição: a propriedade de Sutpen, Sutpen's Hundred - literalmente as Cem Milhas Quadradas de Sutpen -, propriedade a partir da qual Thomas estende seu domínio, é um território de ódio, de violência e, em breve, de morte.

“Um ódio, um ódio vigoroso vai ser sempre dedicado necessariamente a um ser, à entidade que alguém representa - não necessariamente Deus", escreve Lacan (1972-1973/1975, p. 91). Mas, se em Absalão, Absalão! o objeto do ódio é, na verdade, um objeto sempre único, no qual o movimento hostil se focaliza até a incandescência, o ódio propaga-se - por outro lado - de forma hemorrágica no romance, contaminando todos os personagens aos poucos. Mas por que tanto ódio? O que o provoca e por que ele é tão bem cuidado se seu poder de destruição é tão claro? Para além do círculo restrito da família, o destino maldito dos Sutpen 
revela-se uma realidade emblemática de todo o sul dos Estados Unidos e, ainda mais, do mundo colonial em seu conjunto - esse território onde a fronteira entre negros e brancos é tão rija quanto porosa, dando vazão a todas as fascinações e repulsões.

As "pequenas diferenças, mesmo havendo semelhanças (...), constituem os sentimentos de estranheza e de hostilidade", observa Freud em 1918 a respeito do tabu da virgindade (1918/1991, p. 86). Em 1921, em Psicologia das massas e análise do ego, Freud acrescenta que, no aspecto coletivo, a coesão interna do grupo apoia-se sobre a exclusão daqueles que são identificados com a marca da diferenciação (1921/1991). Em Absalão, Absalão! - quer seja um dos escravos curvados nos campos, quer seja Clytie (filha ilegítima de Thomas Sutpen e de uma de suas escravas) -, o negro é sempre visto como o mais estrangeiro - o outro, o alien - e como o mais familiar, aquele que divide o círculo íntimo mais próximo, como a vovó Caroline, a escrava liberta que continuou toda sua vida a serviço da família dos Faulkner e que, durante seu enterro, recebeu homenagem do escritor Faulkner. Entre negros e brancos, nesse Mississipi pobre, a proximidade é necessária e a diferença diminuída à menor proporção possível. No entanto, tão próximo assim e mesmo se ainda mais fosse, o negro sempre será um outro em relação ao branco, um objeto heterogêneo em relação ao sujeito e, por esta mesma razão, objeto hostil, atestando dessa maneira a equivalência freudiana segundo a qual "o externo, o objeto, o odiado seriam idênticos a priori" (FREUD, 1915b/1988, p. 183). Mas o que o universo do romance permite enxergar é o fato desta rejeição não se basear tanto assim sobre a diferença, mas sobre o temor de uma semelhança fundamental. "O negro é o medo que o branco tem de si mesmo", conclui Octave Mannoni, como se numa lápide (1947/1997, p. 298). Desta maneira, o negro é aquele que somos, mas que não podemos reconhecer no espelho que ele nos mostra. Sempre presente (déjà-là), o negro desponta como o próprio paradigma da estranheza inquietante, "esta modalidade do horror cujas raízes vêm da vivência atávica" (FREUD, 1919/1996, p. 152) e que ressurge com a violência própria ao retorno do recalcado. No fundo, próximo assim desta "parte obscura, inacessível de nossa personalidade" (FREUD, 1915-1917/1985, p. 102), o negro - este ser cujo estatuto não pode ser decidido - tem o aspecto terrível do inconsciente na obra de Faulkner.

Mas se o contato entre as mãos negra e branca pode ser assim tão abrasivo, é porque ela atesta uma intimidade virtual, do desejo potencial, do estreitamento possível. Do ódio ao amor, "transformação de uma pulsão em seu antagonista" (S. FREUD, 1915b/1988, p. 180), a distância é de apenas um passo que os homens já haviam ultrapassado, fugindo para os "braços harmoniosos da cor de magnólia" dos mestiços ou das escravas negras (FAULKNER, 1936/1995, p. 875). Entre peles negras e brancas, o corpo-a-corpo multiplica-se desde os combates secretos das negras e de Thomas Sutpen, banhado de sangue na estrabaria da Sutpen's Hundred sob o olhar inquieto de Judith e Henry, até o momento dos coitos cujos frutos foram os dois mestiços Clytie e Charles Bon. Mas curiosamente e ainda por causa de uma estranha reviravolta para o oposto, a exogamia aparente que a diferença de tez de pele manifesta, esconde uma endogamia absoluta que ameaça vir contra a dinastia dos Sutpen e fazê-los decair. O encontro entre Henry Sutpen, o filho legítimo de Thomas Sutpen, e de Charles Bon, o ilegítimo - branco de pele, mas negro segundo a one-drop rule, já que filho de uma mulher com um oitavo de sangue negro - repito, o encontro entre esses dois meio-irmãos que nunca deveriam haver-se encontrado, dá-se em Oxford. Ele leva a um outro encontro, através de Henry, entre Charles Bon e sua meia-irmã Judith; daí nasce uma história de amor não assumido - tímido, mas determinado - que parece levá-los em direção a um casamento incestuoso por uma pura ironia trágica. A revelação feita por Thomas a Henry tem por consequência o assassinato de Charles por Henry, impedindo assim esse casamento abominável. Só que Henry não mata seu meio-irmão em nome do tabu do incesto. Temos esse diálogo entre os dois, pouco antes do assassinato:

- Então, o que não podes tolerar é a mistura das raças e não o incesto...

- És meu irmão.

- Não. Eu sou o negro que vai-se deitar com tua irmã. A não ser que me impeças, Henry. (ibid., p. 912-914) 
A proibição do incesto é, na realidade, levada até o extremo e totalmente desabilitada no romance, como se - no fundo - toda e qualquer união entre brancos só pudesse ser incestuosa e, ainda que homossexual, só pudesse gerar o mesmo do mesmo - concretizando, assim, a fantasia propriamente sulista de uma sociedade que se afunila em direção ao idêntico. Este desabafo de Henry atesta um desejo absoluto de incesto: "Este é talvez o incesto puro e perfeito: o irmão se dando conta que a virgindade de sua irmã deve ser eliminada para que esta possa realmente haver existido e que esta destruição seja perpetrada por seu meio-irmão - o homem que aquele gostaria de ser, caso pudesse metamorfosear-se no amante, no marido; e pelo qual aquele também queria ser tomado, que escolheria para ser seu homem, se ele pudesse metamorfosear-se na irmã, na amante, na esposa" (ibid., p. 690). Nesse mundo endogênico das grandes linhagens do sul, o terror do incesto deu lugar ao pavor absoluto da mistura de raças, horror da miscigenação, em uma aritmética assombrante (mulato, crioulo, tercerão, quarterão, quinterão) - sem que nos esqueçamos das leis complexas e rigorosas dos primitivos que nos apresenta Freud em Totem e tabu (1912/1998), feitas para proibir todo e qualquer intercurso sexual dentro do mesmo clã. Este horror da mistura é tão grande na micro-sociedade d'Absalão, Absalão! ao ponto de privar de origem e de destino as crianças mestiças, condenando-as assim à loucura, à ignorância ou a ambos. Em todo caso, nessa sociedade de ideologia profundamente racista, "a mestiçagem incarna a síntese ruim, a mistura impossivelmente 'correta' entre o mesmo e o outro" (TAGUIEFF, 1991, p. 55).

Vertigem do idêntico, a tentação incestuosa entre negro e branco suspende, então, a ameaça de uma confusão que somente o ódio permite conjurar. Duas meias-irmãs de sangue e sua tia vivendo as três na Sutpen's Hundred durante a Guerra de Secessão, a mestiça Clytie e as brancas Judith e Rosa são uma só pessoa: "era como se fôssemos o único e mesmo ser inconfundível e inseparável" (FAULKNER, 1936/1995, p. 741). Poder-se-ia supor que seria contra todo risco de assimilação - aqui no sentido de múltiplas significações - que a senhorita Rosa batalha assim que declara acerca de Clytie: "Não sei o que Clytie pensava, que vida ela levava (...) Mas eu esperava por isso, pois eu e ela éramos inimigas declaradas e - ainda diria mais - leais" (id.). A negra Clytie e a branca Rosa sempre se mantiveram unidas, não por causa da tez de suas peles, mas antes pelo ódio que reforçasse a diferença fundamental nos planos em que houvesse uma tendência ao amálgama. Tal como as vozes dos narradores que se intercambiam e se confundem, tal como o próprio fraseado faulkneriano, que se estende até não poder mais acabar: aqui, as vozes dos personagens parecem misturarse umas nas outras em um lirismo barroco que as faz integrar à grande voz do mundo. Presos na armadilha de uma ascendência que exclui a diferença e apenas dá conta da interdependência absoluta e transgeracional dos seres, os personagens têm apenas ao ódio para tentar dar existência à sua singularidade.

O ódio descobre finalmente seu semblante real, paixão narcisista que faz do outro, de qualquer pessoa que seja, uma persona non grata que se atreve a adentrar em seu território: "Em relação ao objeto, o ódio é mais antigo que o amor. Ela alimenta-se, desde tempos imemoriais, da recusa do mundo exterior enquanto dispensário de estímulo - recusa essa que emana do ego narcisista" (FREUD, 1915b/1988, p. 186). Mas Thomas Sutpen, o protagonista do romance de Faulkner, parece ser uma figuração exata desse ego freudiano dos tempos imemoriais - um ego autárquico e indiferente, odiando tudo que se lhe dessemelhe: "Ele era agora o maior latifundiário e plantador de algodão daquela região... - sempre tão obstinado e determinado, desdenhando sempre como a gente da cidade tomava seus atos visíveis e interpretava os invisíveis (...) Ninguém gostava dele (coisa que claramente pouco lhe importava), mas ele era temido - coisa que o divertia ou, até mesmo, Ihe dava prazer" (FAULKNER, 1936/1995, p. 668-669). Para instalar e ampliar seu domínio, ele utiliza tudo o que lhe está à mão - inclusive homens e mulheres - e não hesita nem por um momento sequer a livrar-se daqueles que poderiam vir a impedir sua ascensão megalomaníaca, concretizando assim a asserção freudiana segundo a qual: "Todo dia, a toda hora, em nossas atitudes inconscientes, afastamos do nosso caminho aqueles que nos atrapalham, aqueles que nos ofenderam e atacaram (...) pois todo dano absorvido pelo nosso onipotente e soberano ego é, no fundo, um crime de lesa majestade" (1915a/1988, p. 154). Nada pode impedir a pulsão de dominação de Thomas Sutpen, que, tal um conquistador ensandecido, pretende reinar sobre Sutpen's Hundred, um território que se mostra na medida exata de sua desmesura. Ele é, como o diz Quentin a Shreve, "o cavaleiro que, em certa época, possuíra tudo o que ele podia enxergar a partir de um ponto de vista dado: cada ramo de árvore, talo de erva, casco de animal ou sola de homem faziam-lhe lembrar (se por acaso tivesse esquecido) que, tanto aos olhos deles quanto aos seus próprios, era ele o maior de todos" (FAULKNER, 1936/1995, p. 918). 
Desta forma, revela-se aqui uma reprodução bem estranha do próprio Faulkner. Uma vez terminado Absalão, Absalão!, Faulkner rabisca o mapa desta região imaginária de Yoknapatawpha, na qual ele decide inserir todos os seus romances passados e futuros: "Descobri neste recôncavo da minha terra natal, tão grande quanto um selo de correio, um tema valioso, que eu nunca poderia exaurir durante a única vida que me foi dada e, sublimando a realidade para dali tirar esse país apócrifo, eu teria a liberdade total para lhe dedicar o máximo de meu talento. Isto foi para mim a descoberta de uma mina de ouro de personagens, além de todo um universo a mim próprio (a cosmos of my own). Posso fazer viver essa gente, como se fora Deus, não somente no espaço, mas no tempo (...) Gosto de imaginar o mundo que criei como uma espécie de chave magna do universo: não importa quão minúscula fosse, se ela fosse retirada, todo um universo extinguir-seia" (COWLEY, 1967, p. 20). À margem do mapa deste território que Faulkner concebia tendo 2400 milhas quadradas e povoado por 6298 brancos e 9313 negros, o autor escreve: "William Faulkner, único detentor e proprietário".

Winnicott insiste acerca da qualidade profundamente agressiva que abarca a afirmação Eu sou: "O monoteísmo parece ser estreitamente ligado à expressão Eu sou. Sou o que sou. (...) Se sou, quer dizer então que juntei isso e aquilo outro, que me proclamei a mim e que refutei todo o resto; e, refutando o que não seria eu, cometi uma injúria contra o resto do mundo e devo esperar ser atacado a qualquer momento" (1968/1988, p. 81). Se tal agressividade é necessária, seria porque - segundo Winnicott - o conceito de identidade - de unidade do self - é o objeto de um aprendizado complexo: "Para o bebê, há primeiramente uma unidade que inclui a mãe... Em relação a isto, a mãe configura-se então o início de uma ilusão que o bebê deve conseguir refutar e substituir-lhe pela incômoda unidade do eu sou, que necessita da perda da unidade fusional original que é poupada" (ibid., p. 89-90). Pode-se ainda gozar de uma certa ambiguidade semântica que corresponde ao papel particular que o narcisismo do bebê confere à unidade original entre ele e sua mãe; esta unidade é poupada (spared) - ou seja, ou esta seria realocada como numa espécie de poupança bancária que o sujeito poderá reutilizar assim que precisar, ou seria salva da destruição total.

Para Thomas Sutpen, a perda do paraíso original dos braços da mãe - fonte de toda onipotência - coincide com a perda das montanhas da Virgínia, território virgem e edênico que pertence a todos e, ao mesmo tempo, a ninguém - dentro do qual se é livre para ir e vir quando bem quiser. Como sua mãe já tinha morrido havia um bom tempo, a longa caminhada para o sul - verdadeira travessia do deserto - leva a cabo a descoberta da sociedade latifundiária: "Ele nunca tinha ouvido falar, nem imaginado, que existiria um lugar, uma terra, cuidadosamente delimitada e detida por homens que nada mais faziam além de atravessá-la sobre seus belos cavalos ou sentarem-se tranquilamente, vestidos com roupas elegantes, nas varandas de casarões enquanto outros trabalhavam por eles" (FAULKNER, 1936/1995, p. 797). A descoberta de que o território do outro começa onde o território do ego termina age como uma revelação traumatizante. Para Thomas Sutpen, a cena primeira será a visão escondida de um proprietário de terras confortavelmente disposto em sua rede e servido por um negro tão bem vestido quanto nunca o será novamente em sua vida. Thomas descobre aqui a inveja, origem kleiniana do ódio. A cena iniciática, que foi para Faulkner a própria inspiração para o romance, é a seguinte: a humilhação de ser mandado, com uma mensagem em mãos, para as portas de trás da belíssima casa do proprietário por um negro muito bem vestido, em contraste com os farrapos que o protagonista levava consigo. Na noite seguinte, ele delibera consigo mesmo: "Então, para os combater, deves possuir tudo o que leva aquele homem a ser daquele jeito. Você deve possuir terras, negros e uma casa grande para que combatas os demais. Entendeste? (...) E ele nunca mais reviu sua família" (ibid., p. 812).

Desinvestindo-se completamente de seus próximos sem criar, contudo, novos laços de objeto com outras pessoas, Thomas Sutpen põe-se a serviço da pulsão de morte, como constata Freud em $O$ ego e $o$ id: se, a partir daí, "o narcisismo do ego é, logo, um narcisismo secundário, extraído dos objetos" (1923/1991, p. 289), nada mais impedirá "a pulsão de destruição que o ódio passa a guiar" (ibid., p. 285). Diante da tentação unitária, a alteridade do objeto desaparece e alguns negros vão até mesmo perder o semblante humano, tornando-se "uma bexiga com uma cara pintada nela - um rosto reluzente e plano - cheia de ar e ao ponto de estourar-se de rir: ninguém se atreve a tocá-la por medo de arrebentá-la" (FAULKNER, 1936/1995, p. 807). Assim, como destaca Octave Mannoni, "o 'colono' não está apenas atrás do lucro, mas também de outras maneiras mais perigosas de satisfazer-se" (1947/1997, p. 69). O ódio completa seu trabalho de mortificação, não sempre através de um desencadeamento violento, mas no silêncio relativo de uma indiferença para com o objeto que solidifica sua destituição em prol da onipotência do ego. Durante esse tempo, os cadáveres acumulam-se - os da família de Sutpen e outros da Guerra de Secessão -, condenando os sulistas mortos a 
serem apenas fantasmas penados em busca de um tempo edênico que não existe ou talvez nunca haja realmente existido. Infanticídio, fratricídio, parricídio, nada mais falta aos Sutpen para que entrem no círculo restrito das grandes linhagens da tradição trágica sobre as quais a fatalidade abate-se com todo seu peso em uma sucessão interminável de ódio e ressentimento: "Meu filho Absalão! Absalão, meu filho! Meu filho Absalão! Queria haver morrido em teu lugar!". O título do romance - eco do rei David lamentando-se pela morte de seu filho rebelde, Absalão - faz suspender o remorso amargo do assassinato do filho - o assassinato por excelência - sobre a dinastia de Thomas Sutpen, que será descrito por Faulkner como -um homem que queria, por orgulho, ter um filho e só o teve quando este foi destruído- (FAULKNER, 1964, p. 87).

"O ódio é obscuro. Ele ignora o que o anima e deve ignorá-lo para se perpetuar. O ódio é ilegítimo e tem consciência disso. Inclusive, é a única coisa que sabe de si. É por isto que ele tenta incansavelmente legitimarse", escreve Pontalis (1988, p. 55). Se o sul cai no caos absoluto em Absalão, Absalão!, não seria por que, no fundo, o desenvolvimento da sociedade dos latifundiários sulistas baseou-se na expropriação da terra, roubada dos povos indígenas? Esta ilegitimidade da fundação do território, esta violência não atingiria necessariamente a sucessão de atos de violência e de ódio? Ao renomear o condado de Lafayette "condado de Yoknapatawpha", Faulkner faz ressurgir o recalque indígena. A escolha deste nome indígena, que significa "terra dividida" na língua chikasaw faz lembrar - verdadeiro retorno do recalque - a origem indígena da terra e, por consequência, o roubo que constitui sua apropriação pelos brancos. Este gesto de monopolização dos primeiros colonos é reapropriado por Sutpen, "este Fausto que apareceu bruscamente em um domingo, com duas pistolas e vinte demônios às suas ordens, enganou um pobre indígena estúpido para lhe extorquir cem milhas quadradas de terra e edificou nesta terra o maior casarão jamais ali visto" (FAULKNER, 1936/1995, p. 761). Ao contar a história apócrifa do sul - esta inversão da história oficial -, Faulkner narra, de um romance ao outro, cada uma das vidas plenas de barulho e de furor que só podem ser consequência do gesto fundador, ilegítimo e violento (como talvez todo e qualquer ato fundador), mas não reconhecido como tal e não havendo levado a nenhum sentimento de culpa, mas, pelo contrário, à reprodução do crime de espoliação através da escravidão dos negros.

A propósito de Absalão, Absalão!, que ele considera "o melhor romance jamais escrito por um americano", Faulkner escreve a seu editor: "Em resumo, o tema central é a vida de um homem que violentou a terra; então, esta mesma terra voltou-se contra ele e destruiu sua família" (Carta de Faulkner para Harrison Smith, fevereiro de 1934, ibid., p. 1328). A terra - sem dúvidas, a verdadeira protagonista do romance -, sua terra natal, esta terra do sul onde mora cada um dos narradores que se propõem testemunhar sobre a epopeia dos Sutpen. Terra violentada, estuprada, ela é o teatro da luta sem fim entre forças contrárias, repetindo uma cena primitiva monstruosa cujo eco ensurdecedor não parece parar de assombrar os personagens, como o grito do bugre idiota que continua a ecoar quando tudo é aniquilado. Acerca da terra, Freud diz que ela é uma das figurações possíveis da mãe de cada homem, "Mãe-terra que o acolhe mais uma vez" $(1913 / 2005$, p. 65) quando tudo acaba. "Ei-lo de volta ao seu lar, em sua terra natal. Ele lhe é grato pela vida concedida e ali descansarão seus ossos", escreve Faulkner em seu ensaio sobre o Mississipi (1969, p. 52). Para Faulkner, a afinidade profunda entre a mãe e a terra incarna-se na casa, centro do qual tudo parte e tudo retorna, a forma concreta dos sonhos e das esperanças de homens e mulheres, espaço consubstancial e íntimo: "a casa que ele construíra, de não se sabe qual supuração havia sido criada entorno dele, tal como se o suor de seu corpo pudesse haver criado e produzido um casulo (ainda que invisível), uma carapaça complementar" (FAULKNER, 1936/1995, p. 727). Quando a casa é consumida pelas chamas em Absalão, Absalão!, como se num apocalipse de um grande incêndio bíblico surgido para purificar a terra da impureza humana, vemos um astro que se põe, uma civilização que chega ao cabo, na sequência linear da derrota na Guerra de Secessão, abrindo assim a via para o que Ihe sucederá, o caminho dos filhos mestiços: "Creio que um dia os Jim Bond dominarão a esfera ocidental. Claro que isto não se dará de imediato e claro que eles migrarão para os pólos, embranquecer-seão, tais como coelhos e pássaros, a fim de não serem vistos em meio à neve. Mas será a vez de Jim Bond - e tanto o é que, em alguns milhares de ano, eu mesmo terei a minha linhagem traçada diretamente com a de algum rei africano" (ibid., p. 931).

Mas, por trás (ou talvez para além) do ódio que ele inspira e encena, sem que assim o anule, o sul é o objeto do amor mais violento em Absalão, Absalão!. No entanto, nada é dito acerca deste amor, nenhum desenvolvimento do enredo, nem belas fórmulas, nem declarações inflamadas. Apenas, ao fim do romance, estas últimas palavras, como uma denegação, um litote, um grito mudo que fala de amor ensandecido: “Agora eu só queria que me dissesses uma coisa. Por que odeias o sul? Mas eu não o odeio, - respondeu Quentin 
veemente, imediatamente. Eu não o odeio, disse ele. Eu não o odeio, ele pensou, arquejando no ar glacial, na escuridão implacável da Nova Inglaterra; Não. Não! Não o odeio! Não o odeio!" (ibid., p. 932). Amor profundo, arcaico, amor do primeiro objeto, a mãe, transformada em terra natal sobre a qual se deve estender seu domínio, fundar seu território. Privado de uma lei paterna arbitrária e simbólica que viesse a concretizar a proibição do incesto, mas - ao contrário - baseada em uma lei ensandecida, a one-drop rule, que imita o ego materno narcisista do idêntico imutável, o sul dos Estados Unidos é, no início do século XX, uma terra sobre a qual o ódio é levado a desenvolver-se através da exploração escravocrata. $O$ ódio racial que se desenvolve neste território é, sem nenhuma margem de dúvidas, na medida exata do amor primeiro; um amor sem nuances, nem medidas; um amor que justifique todas as exclusões, exatidões, destruições.

Recebido em: 30 de julho de 2015. Aprovado em: 3 de dezembro 2015.

\section{REFERÊNCIAS}

COWLEY M. Romanciers au travail. Paris: Gallimard, 1967.

FAULKNER W. Absalon, Absalon! (1936). In : CEuvres complètes, II, Paris: Gallimard (coleçao La Pléiade), 1995.

Faulkner à l'Université, Paris: Gallimard, 1964.

Essais, discours et lettres ouvertes. Paris: Gallimard, 1969.

FREUD, S. Actuelles sur la guerre et la mort (1915a). Tradução francesa sob a direção de J. Laplanche. Paris: PUF, 1988. (đEuvres completes, 13).

. Leçons d'introduction à la psychanalyse (1915-1917). Tradução francesa sob a direção de J. Laplanche. Paris: PUF, 1985. (đEuvres completes, 14).

Le moi et le ça (1923). Tradução francesa sob a direção de J. Laplanche. Paris: PUF, 1991. (đEuvres completes, 16).

Le motif du choix des coffrets (1913). Tradução francesa sob a direção de J. Laplanche. Paris: PUF, 2005. (đFuvres completes, 12).

Le tabou de la virginité (1918). Tradução francesa sob a direção de J. Laplanche. Paris: PUF, 1996. (CEuvres completes, 15).

L'inquiétant (1919). Tradução francesa sob a direção de J. Laplanche. Paris: PUF, 1996. (CEuvres completes, 15).

Psychologie des masses et analyse du moi (1921). Tradução francesa sob a direção de J. Laplanche. Paris: PUF, 1991. (Geuvres completes, 16).

Pulsions et destins des pulsions (1915b). Métapsychologie. Tradução francesa sob a direção de J. Laplanche. Paris: PUF, 1988. (๔euvres completes, 13).

Totem et tabou (1912). Tradução francesa sob a direção de J. Laplanche. Paris: PUF, 1998. (๔uuvres completes, 11).

LACAN, J. Encore (1972-1973). Paris: Editions du Seuil, 1975. (Le Séminaire, 20).

MANNONI, O. Le racisme revisité (1947). Paris: Denoël, 1997.

PERETZ, P. L'Amérique post-raciale. Paris: PUF, 2013.

PONTALIS, J.-B. Perdre de vue. Paris: Gallimard (coleção Folio), 1988.

TAGUIEFF, P.-A. Doctrines de la race et hantise du métissage, fragments d'une histoire de la mixophobie savante. Nouvelle revue d'ethnopsychiatrie, 17, 1991.

WINICCOTT, D.-W. Conversations ordinaires (1968). Paris: Gallimard (coleção Folio), 1988. 
Isée Bernateau

isee.bernateau@orange.fr

Márcio de Oliveira Bezerra

marciodoliveira@gmail.com

\section{Thomas Seillier}

thomas.seillier@hotmail.fr.

Traduzido do francês para o português por Márcio de Oliveira Bezerra. Universidade Clermont Auvergne, Mestre pela Faculdade de Letras, Línguas e Ciências Humanas, Auvergne-Rhône-Alpes, França.

Traduzido do francês para o inglês (abstract) por Thomas Seillier. Universidade Paris IV Paris-Sorbonne, Graduado no Laboratório de Vozes Anglofônicas, Literatura e Estética, Paris, França. 